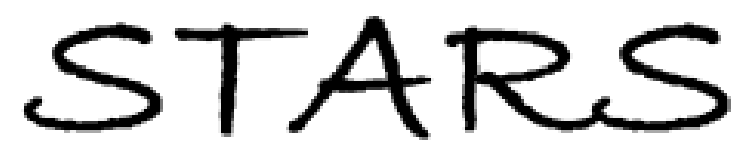

University of Central Florida

STARS

$1-1-2010$

\title{
Multistate modeling of habitat dynamics: factors affecting Florida scrub transition probabilities
}

David R. Breininger

University of Central Florida

James D. Nichols

Brean W. Duncan

University of Central Florida

Eric D. Stolen

Geoffrey M. Carter

See next page for additional authors

Find similar works at: https://stars.library.ucf.edu/facultybib2010

University of Central Florida Libraries http://library.ucf.edu

This Article is brought to you for free and open access by the Faculty Bibliography at STARS. It has been accepted for inclusion in Faculty Bibliography 2010 s by an authorized administrator of STARS. For more information, please contactSTARS@ucf.edu.

\section{Recommended Citation}

Breininger, David R.; Nichols, James D.; Duncan, Brean W.; Stolen, Eric D.; Carter, Geoffrey M.; Hunt, Danny K.; and Drese, John H., "Multistate modeling of habitat dynamics: factors affecting Florida scrub transition probabilities" (2010). Faculty Bibliography 2010s. 7018.

https://stars.library.ucf.edu/facultybib2010/7018

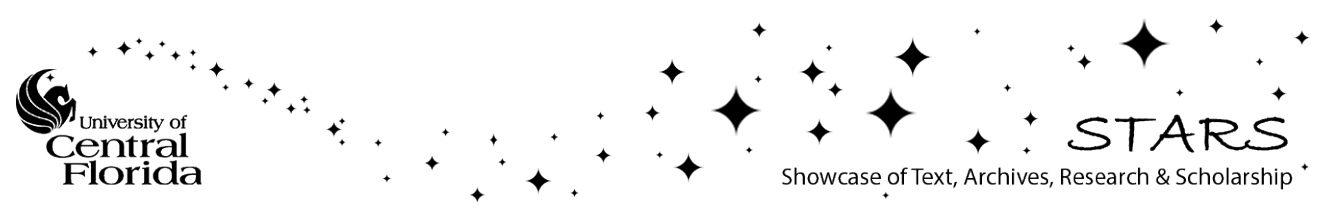




\section{Authors}

David R. Breininger, James D. Nichols, Brean W. Duncan, Eric D. Stolen, Geoffrey M. Carter, Danny K. Hunt, and John H. Drese 


\title{
Multistate modeling of habitat dynamics: factors affecting Florida scrub transition probabilities
}

\author{
David R. Breininger,,${ }^{1,2,4}$ James D. Nichols,${ }^{3}$ Brean W. Duncan, ${ }^{1,2}$ Eric D. Stolen,,${ }^{1}$ Geoffrey M. Carter, ${ }^{1}$ \\ Danny K. Hunt, ${ }^{1}$ and John H. Drese ${ }^{1}$ \\ ${ }^{1}$ Innovative Health Applications, IHA-300, Kennedy Space Center, Florida 32899 USA \\ ${ }^{2}$ Department of Biology, University of Central Florida, 4000 Central Florida Boulevard, Orlando, Florida 32816 USA \\ ${ }^{3}$ United States Geological Survey, Patuxent Wildlife Research Center, Laurel, Maryland 20708 USA
}

\begin{abstract}
Many ecosystems are influenced by disturbances that create specific successional states and habitat structures that species need to persist. Estimating transition probabilities between habitat states and modeling the factors that influence such transitions have many applications for investigating and managing disturbance-prone ecosystems. We identify the correspondence between multistate capture-recapture models and Markov models of habitat dynamics. We exploit this correspondence by fitting and comparing competing models of different ecological covariates affecting habitat transition probabilities in Florida scrub and flatwoods, a habitat important to many unique plants and animals. We subdivided a large scrub and flatwoods ecosystem along central Florida's Atlantic coast into 10-ha grid cells, which approximated average territory size of the threatened Florida Scrub-Jay (Aphelocoma coerulescens), a management indicator species. We used 1.0-m resolution aerial imagery for 1994, 1999, and 2004 to classify grid cells into four habitat quality states that were directly related to Florida Scrub-Jay source-sink dynamics and management decision making. Results showed that static site features related to fire propagation (vegetation type, edges) and temporally varying disturbances (fires, mechanical cutting) best explained transition probabilities. Results indicated that much of the scrub and flatwoods ecosystem was resistant to moving from a degraded state to a desired state without mechanical cutting, an expensive restoration tool. We used habitat models parameterized with the estimated transition probabilities to investigate the consequences of alternative management scenarios on future habitat dynamics. We recommend this multistate modeling approach as being broadly applicable for studying ecosystem, land cover, or habitat dynamics. The approach provides maximum-likelihood estimates of transition parameters, including precision measures, and can be used to assess evidence among competing ecological models that describe system dynamics.

Key words: Aphelocoma coerulescens; capture-recapture; disturbance; fire; Florida Scrub-Jay; Kennedy Space Center/Merritt Island National Wildlife Refuge, Florida, USA; land cover; multistate models; patch dynamics; restoration; scrub.
\end{abstract}

\section{INTRODUCTION}

Land cover, vegetation, and habitat are frequently viewed as primary determinants of both the distribution (e.g., Scott et al. 1993) and abundance (e.g., Van Horne 1983) of animal populations. Analyses relating habitat covariates to animal occurrence retain a prominent place in ecological and conservation literature (Scott et al. 2002). Traditionally, it has been common to view landscape features and animal populations as static entities, but many other questions focus instead on dynamics, including climate change, ecological succession, and habitat management (Hodgson et al. 2009).

Successional dynamics are important determinants of the dynamics and persistence of animal populations inhabiting such habitats (Thomas 1994, Amarasekare

Manuscript received 1 June 2009; revised 16 February 2010; accepted 9 March 2010. Corresponding Editor: J. R. Sauer.

${ }^{4}$ E-mail: david.r.breininger@nasa.gov and Possingham 2001, Ellner and Fussmann 2003). Managing animal populations and communities associated with transitional habitats (habitats that do not represent endpoints of succession, or climax) requires efforts to mimic natural disturbance regimes to retain habitats in transitional stages (Breininger et al. 2009).

A variety of approaches have been used to model habitat dynamics (Baker 1989). Markov models provide a useful framework for modeling dynamics in cases in which relevant landscape and habitat features can be adequately characterized by discrete stages or states (e.g., Waggoner and Stephens 1970, Usher 1979, Callaway and Davis 1993). In such models, the state of the system at one point in time is written as a function of the state of the system at a previous time, together with a set of state transition probabilities representing the different possible types of habitat change.

The key inferential step in the use of Markov models is estimation of the transition probabilities that govern change. In some cases, values for transition probabilities 
have been based on expert opinion (Fonnesbeck 2006). In other cases, output from more detailed models of dynamic processes (e.g., regeneration and mortality of individual trees) occurring within sites can be aggregated to draw inferences about the "state changes" of the sites (e.g., Acevedo et al. 1996).

In many cases, transition probabilities can be estimated from data comprised of states recorded at the same sites for multiple time periods. There are multiple ways to estimate transition probabilities from such data, but many are based on closed-form estimators that focus on one state transition at a time or on multiple transitions from one state to other states (e.g., Augustin et al. 2001, Yemshanov and Perera 2003, Rutherford et al. 2007). An efficient, alternative approach is to use maximum-likelihood methods to model the entire set of site history data, where the data reflect the state of each site at each time period of observation. Such models are parameterized using transition probabilities that can themselves be modeled as constants, time varying, or functions of ecological covariates.

We develop this approach for estimating habitat transition probabilities as a special case of multistate capture-recapture models that have been used to address many questions regarding ecology and evolution (Nichols et al. 1994, Nichols and Kendall 1995, Lebreton et al. 2009). We show the relationship between multistate capture-recapture models and Markov models of transition probabilities for habitat dynamics using software that facilitates modeling the effects of covariates on the spatial and/or temporal variation in transition probabilities (White and Burnham 1999, White et al. 2006). This approach uses competing ecological models in a likelihood framework permitting model selection, model averaging, and related approaches to multimodel inference (Buckland et al. 1997, Burnham and Anderson 2002).

We apply multistate models to the dynamics of Florida scrub and flatwoods habitat to estimate habitat transition probabilities and test predictions about factors that influence transitions, including disturbances, management actions (i.e., fire and mechanical cutting), and landscape characteristics (vegetation, edge). We will also use these transition probability estimates to explore the range of relative abundances of habitat states in the future under several management scenarios. The four habitat states we use in this modeling directly influence recruitment, survival, and source-sink dynamics of Florida Scrub-Jay (Aphelocoma coerulescens) populations (Breininger and Carter 2003, Breininger and Oddy 2004; see Plate 1). In addition to being of interest as a threatened species under the Endangered Species Act, the Florida Scrub-Jay is an indicator and flagship species of scrub habitat (Noss et al. 1997). Scrub and flatwoods have been greatly degraded by anthropogenic reductions in natural fire frequency, and restoring and managing them are important to conserving many unique plant and animal populations (Quintana-Ascencio and Menges 1996, Duncan et al. 1999, Duncan and Schmalzer 2004, Breininger et al. 2006, Menges et al. 2008).

\section{Background And Hypotheses \\ Modeling habitat dynamics}

We modeled habitat dynamics at the scale of 10-ha grid cells that represented average Florida Scrub-Jay territories in a landscape (Breininger et al. 2006). Habitat states included short, optimal, tall mixed, and tall, denoted as, respectively, Sh, Op, Tm, and Ta. The Op state has Florida Scrub-Jay recruitment that exceeds mortality and is a mix of short and medium-height oaks, which provides optimal acorn production, nesting cover, and predator escape cover. Other states have mortality that exceeds recruitment because they are either too short or have too much tall, dense scrub (Breininger et al. 2009).

Markov models of habitat dynamics are similar to projection models for population dynamics (e.g., Caswell 2001) and Markov models for occupancy dynamics of metapopulations (e.g., Martin et al. 2009a). For a system of sites, define a vector as the number of sites in each of the four possible habitat states $\left(n_{t}^{\mathrm{Sh}}, n_{t}^{\mathrm{Op}}, n_{t}^{\mathrm{Tm}}\right.$, $\left.n_{t}^{\mathrm{Ta}}\right)$ at a given time period, $t$. Transition probabilities $\left(\psi_{t}^{r s}\right)$ are defined as the probability that a site in state $r$ at time $t$ is in state $s$ at time $t+1$. A projection model for habitat dynamics can then be written as

$$
\left[\begin{array}{c}
n_{t+1}^{\mathrm{Sh}} \\
n_{t+1}^{\mathrm{Op}} \\
n_{t+1}^{\mathrm{Tm}} \\
n_{t+1}^{\mathrm{Ta}}
\end{array}\right]=\left[\begin{array}{llll}
\psi_{t}^{\mathrm{ShSh}} & \psi_{t}^{\mathrm{OpSh}} & \psi_{t}^{\mathrm{TmSh}} & \psi_{t}^{\mathrm{TaSh}} \\
\psi_{t}^{\mathrm{ShOp}} & \psi_{t}^{\mathrm{OpOp}} & \psi_{t}^{\mathrm{TmOp}} & \psi_{t}^{\mathrm{TaOp}} \\
\psi_{t}^{\mathrm{ShTm}} & \psi_{t}^{\mathrm{OpTm}} & \psi_{t}^{\mathrm{TmTm}} & \psi_{t}^{\mathrm{TaTm}} \\
\psi_{t}^{\mathrm{ShTa}} & \psi_{t}^{\mathrm{OpTa}} & \psi_{t}^{\mathrm{TmTa}} & \psi_{t}^{\mathrm{TaTa}}
\end{array}\right]\left[\begin{array}{c}
n_{t}^{\mathrm{Sh}} \\
n_{t}^{\mathrm{Op}} \\
n_{t}^{\mathrm{Tm}} \\
n_{t}^{\mathrm{Ta}}
\end{array}\right]
$$

or, in matrix notation, as

$$
\mathbf{n}_{t+1}=\Psi_{t} \mathbf{n}_{t} .
$$

Thus, we can project the number of sites in each habitat state in one period as a function of the number of sites in each state the previous period and the transition matrix defining the state dynamics. Just as the study of population dynamics focuses on the vital rates (rates of birth, death, and migration) that define such dynamics, the study of habitat dynamics should focus on the transition probabilities $\psi_{t}^{r s}$ that constitute the vital rates of these dynamics (Boughton and Malvadkar 2002).

\section{Factors influencing habitat dynamics}

Ecological hypotheses about factors influencing habitat dynamics were investigated by modeling transition probabilities as functions of single factors or certain combinations of factors (Appendix A). One simple model stated that transitions between habitat states were dependent only on the presence/absence of fire during the interval between transitions because changes 
in habitat structure occur when fires kill most aboveground stems and leaves of dominant plants (Schmalzer and Hinkle 1992). Another simple model includes not only fire, but also the presence/absence of mechanical cutting ("cutting") to enhance fire spread, because habitat that has been degraded by long periods of reduced fire frequency burns poorly (Schmalzer and Boyle 1998). Other factors that influence fire spread, and therefore might influence transition probabilities, include vegetation composition (oak), edge effects (edge), and presence/absence of fire in previous time steps (history). Oak is an important factor because of its presence as a dominant plant cover $(\geq 50 \%$ canopy cover) that distinguishes scrub from flatwoods (Breininger et al. 2002). Edges disrupt fire propagation across landscapes (Duncan et al. 1999) and may be useful for describing variation in transition probabilities. We defined edges as scrub or flatwoods that were adjacent to forest, human-dominated land cover types, or water bodies.

\section{Methods}

\section{Study areas}

We studied areas managed with controlled fires at Kennedy Space Center/Merritt Island National Wildlife Refuge located along central Florida's Atlantic coast (Breininger and Carter 2003). Scrub occurs on relict dunes and is dominated by less flammable scrub oaks (Quercus myrtifolia, Q. geminata) that are among flammable flatwoods vegetation, such as palmetto (Serenoa repens), shiny lyonia (Lyonia lucida), and wiregrass (Aristida stricta; Breininger et al. 2002). Recently burned scrub and flatwoods have an open tree canopy of slash pine (Pinus elliotii). The pines are resilient to most fires, and grasses and shrubs sprout rapidly after fire so that plant species composition changes little in frequently burned areas (Schmalzer and Hinkle 1992). The contemporary fire regime fire cycle (time required to burn an area equivalent to the entire study area) is 14 years (Duncan et al. 2009), but the fire return interval can be as often as 3-5 years in some areas (Breininger et al. 2002).

Anthropogenic land cover alterations began reducing fire frequency 50 years ago (Duncan and Schmalzer 2004). From 1960 to 1980 the study site went through a period during which controlled fires did not occur and wild fires were extinguished. These reductions in burning caused much scrub, flatwoods, and interspersed marshes to transition into forest, which were once rare but are now common (Duncan et al. 1999, 2004). Forests burn poorly and cause fire shadows in scrub and flatwoods downwind (Breininger et al. 2002). Since 1980, controlled fires have been used by the U.S. Fish and Wildlife Service to manage fuels and wildlife habitat; natural fires must generally be suppressed. Fire history data suggest that natural fires were usually frequent and small, having burned under wetter meteorological conditions (i.e., lightning storms) than controlled fire regimes (Duncan 2009).

\section{Data collection}

The habitat quality state of 10-ha grid cells was classified using 1.0-m resolution digital orthophoto quads available in 1994, 1999, and 2004 (Breininger et al. 2006, 2009, Carter et al. 2006). For each of the three sampled years, we classified every grid cell $(n=924)$ into one of four habitat states. The short state (Sh) was identified by grid cells being burned completely within three years, having open sand visible between individual oak shrubs and no patches of medium-height oaks (1.2$1.7 \mathrm{~m}$ tall) larger than 0.4 ha. The optimal state $(\mathrm{Op})$ had an abundance of open sandy areas among mediumheight patches of oak scrub that were $>0.4$ ha in size, but no patches of tall oaks $(>1.7 \mathrm{~m}$ ) larger than 0.4 ha. Medium-height patches were usually 3-20 years postfire and lacked open sandy areas and had interlocking shrub canopies and a smooth texture (Paine 1981) on 1.0-m resolution aerial photography. Smooth texture contrasted with the shadows and tones that create a rough texture for tall oaks on $1.0-\mathrm{m}$ resolution aerial photography. The tall mixed state (Tm) had short or medium-height scrub patches among patches of tall oaks $>0.4$ ha in size. Tall oaks had rough texture on $1.0-\mathrm{m}$ resolution aerial photography and were usually $>15$ years postfire. The tall state (Ta) lacked short and medium-height oaks and usually lacked open sand, except along man-made clearings.

We assigned habitat states for 1994, 1999, and 2004 as a row vector of habitat states for each 10-ha cell. For example, the habitat history for cell $j$ can be written as $h_{j}$ $=($ Sh Op Op), indicating a site that was in short habitat in 1994 and optimal habitat in 1999 and 2004. The data set consisted of such habitat histories for each of the 924 cells. We assumed perfect classification at each period for our analysis and discuss our rationale and approaches to deal with nonnegligible state misclassification in Appendix B.

We used vectors of static (not time-varying) and dynamic (period-specific) covariates predicted to influence transition probabilities in the habitat history of each cell. The static covariate "oak" distinguished grid cells that intersected well-drained oak scrub from those that only occurred on poorly drained flatwoods soils using Brevard County soils maps (Breininger et al. 1991). The covariate "fire" distinguished whether grid cells burned and was specific to each cell for each time period. Fire during the interval $t$ to $t+1$ was used to model the transition probability over the same period, $\psi_{t}^{r s}$. The covariate "cutting" distinguished grid cells that had been subject to mechanical cutting of trees and shrubs (Schmalzer and Boyle 1998). This was also a dynamic covariate, with cutting during the interval $(t, t+$ 1) potentially influencing $\psi_{t}^{r s}$. The covariate "history" identified whether the grid cell burned during the prior five-year interval. History was also a dynamic covariate, 
but in this case fire history during $t-1$ to $t$ potentially affected $\psi_{t}^{r s}$. Burning was determined using habitat management records and remote sensing and was based on whether at least one-quarter of the grid cell was burned or cut (Shao and Duncan 2007, Duncan et al. 2009). The static covariate "edge" distinguished grid cells that intersected human landcover types (e.g., roads), open water, and forests from interior grid cells.

\section{Multistate habitat modeling}

We used the site-specific habitat states and corresponding covariates for each of the 924 10-ha grid cells, for each of three years, 1994, 1999, and 2004, as data to develop habitat models. The first decision in modeling the data was about the relevant timescale. As the data were from three years spaced at five-year intervals, it was natural to estimate five-year transition probabilities corresponding to the interval between samples. We used this approach in this paper, although we show in Appendix B how to draw inferences about mean annual transition probabilities by modeling detection parameters differently. This latter approach can also be modified to model data when state assignment for some cells occurs at different periods than for other cells.

Inferences about habitat dynamics were based on modeling the interval-specific transition parameters, $\psi_{t}^{r s}$. For all sites in each possible state $r$ at time $t$, the probability that the site would be in any of the four states $(s)$ at time $t+1$ followed a multinomial distribution (see also Augustin et al. 2001). Because our data on habitat states of sites were available for three specific years, our inferences about time specificity of transition probabilities were limited. We estimated five-year transition probabilities for the first five-year period (1994-1999; denoted as $\psi_{94}^{r s}$ ) and the second fiveyear period (1999-2004; denoted as $\psi_{99}^{r s}$ ) for all habitat states. The resulting estimated transition probabilities can be combined into transition matrices and used to project habitat change following: $\mathbf{n}_{99}=\boldsymbol{\Psi}_{94} \mathbf{n}_{94}, \mathbf{n}_{04}=\boldsymbol{\Psi}_{99}$ $\mathbf{n}_{99}$.

Comparing models of habitat transition probabilities.We used program MARK (version 5.1; White and Burnham 1999) to compute maximum-likelihood estimates of the transition probabilities and the parameters associated with covariate relationships.

In addition to providing estimates of habitat state transition probabilities, our modeling approach permits inference about covariates that might influence these probabilities. For example, if $x_{t j}$ indicates a covariate associated with time period $t$ and site $j$, then we can model the corresponding transition probabilities as

$$
\psi_{t j}^{r s}=\frac{e^{\left(\beta_{0}+\beta_{1} x_{t j}\right)}}{1+e^{\left(\beta_{0}+\beta_{1} x_{t j}\right)}}
$$

where $\beta_{0}$ (intercept) and $\beta_{1}$ are parameters of the model and are estimated directly. The $\beta_{1}$ parameters pertain to the nature and strength of the relationship between transition probabilities and the covariate, $x_{t j}$. Although

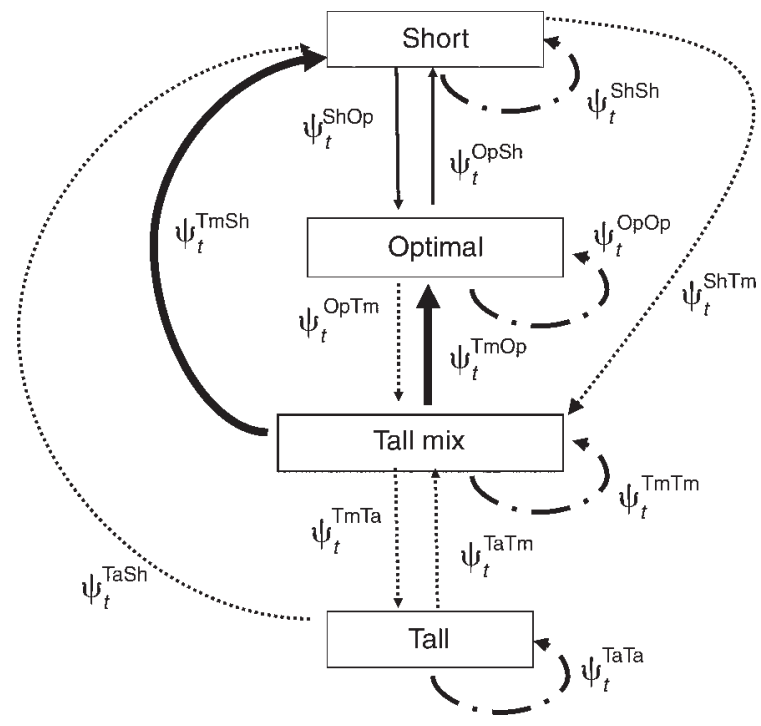

FIG. 1. Transitions and associated probabilities estimated by multistate modeling of scrub and flatwoods at the Kennedy Space Center, Florida, USA, 1994-2004. The superscripts refer to short, optimal, tall mixed, and tall states denoted as, respectively, Sh, Op, Tm, and Ta. Transitions depicted by heavy solid lines had adequate sample sizes for models including all covariates. Transitions depicted by thin solid lines occurred infrequently and were modeled using fewer covariates. Transitions with dotted lines had few occurrences and were modeled using only the covariate oak. Transitions from short to tall, optimal to tall, and tall to optimal habitat states for Florida Scrub-Jays never occurred and were constrained to zero to aid numerical estimation. Transition probabilities for states that remained the same were estimated by subtraction.

we tended to use the above type of linear-logistic model, we could have used multinomial logit models as well. (See also Augustin et al. [2001] for a discussion of these two approaches.) Because

$$
\sum_{s} \psi_{t}^{r s}=1
$$

we always obtained one of the transition probability estimates by subtraction, specifically

$$
\hat{\psi}_{t}^{r r}=1-\sum_{s \neq r} \hat{\psi}_{t}^{r s} .
$$

To avoid numerical estimation problems, we constrained transition parameters to 0.0 when the specific transitions did not occur in the data $\left(\psi^{\mathrm{ShTa}}, \psi^{\mathrm{OpTa}}\right.$, $\left.\psi^{\mathrm{TaOp}}\right)$, and we limited the number of covariates for particular transitions where data were sparse. We included all possible covariates (i.e., the most general models) only for $\psi^{\mathrm{TmSh}}$ and $\psi^{\mathrm{TmOp}}$, because only these transitions had abundant data across all covariate values (Fig. 1). We only included the covariate oak and no other covariates for $\psi^{\mathrm{ShTm}}, \psi^{\mathrm{OpTm}}, \psi^{\mathrm{TmTa}}, \psi^{\mathrm{TaSh}}$, and $\psi^{\mathrm{TaTm}}$ because these transitions were rare, and there were many samples for both oak categories because this covariate identified the two types of plant communities. 
TABLE 1. Comparing the $\hat{\beta}_{j}$ of the best multistate habitat transition model (oak $\times$ fire + oak $\times$ cutting + edge) with a priori predictions for the Kennedy Space Center, Florida, USA, 1994-2004.

\begin{tabular}{|c|c|c|c|c|c|c|}
\hline$\beta_{j}$ description & $\psi$ & $\hat{\beta}_{j}$ & Lower CL & Upper CL & $\begin{array}{l}\text { A priori } \\
\text { prediction }\end{array}$ & Explanations \\
\hline Flatwoods not scrub & $\psi^{\text {ShOp }}$ & 0.32 & -1.04 & 1.69 & - & $\begin{array}{l}\text { disagreement; perhaps flatwoods grew faster } \\
\text { than scrub }\end{array}$ \\
\hline Flatwoods not scrub & $\psi^{\mathrm{ShTm}}$ & -0.37 & -2.35 & 1.62 & - & $\begin{array}{l}\text { agreement; flatwoods were more likely to } \\
\text { burn before getting tall compared to scrub }\end{array}$ \\
\hline Fire vs. no fire in scrub & $\psi^{\text {ShOp }}$ & -0.45 & -1.71 & 0.81 & - & $\begin{array}{l}\text { agreement; scrub that burned was less likely } \\
\text { to increase in height }\end{array}$ \\
\hline $\begin{array}{l}\text { Fire vs. no fire in } \\
\text { flatwoods }\end{array}$ & $\psi^{\text {ShOp }}$ & -1.95 & -2.91 & -0.98 & - & $\begin{array}{l}\text { agreement; flatwoods that burned were } \\
\text { less likely to increase in height }\end{array}$ \\
\hline Edge vs. no edge & $\psi^{\mathrm{ShOp}}$ & 1.16 & 0.44 & 1.88 & + & agreement; edges had less extensive fire \\
\hline Flatwoods not scrub & $\psi^{\mathrm{OpSh}}$ & 0.68 & 0.02 & 1.35 & + & $\begin{array}{l}\text { agreement; flatwoods burned more } \\
\text { extensively than scrub }\end{array}$ \\
\hline Flatwoods not scrub & $\psi^{\mathrm{OpTm}}$ & 1.12 & 0.28 & 1.97 & + & $\begin{array}{l}\text { agreement; flatwoods grew faster than } \\
\text { scrub }\end{array}$ \\
\hline Edge vs. no edge & $\psi^{\mathrm{OpSh}}$ & -0.33 & -0.98 & 0.33 & - & agreement; edges burned less completely \\
\hline Flatwoods not scrub & $\psi^{\mathrm{TmSh}}$ & 0.73 & -1.50 & 2.95 & + & $\begin{array}{l}\text { agreement; flatwoods burned more } \\
\text { extensively than scrub }\end{array}$ \\
\hline Fire vs. no fire in scrub & $\psi^{\mathrm{TmSh}}$ & 2.44 & 0.42 & 4.46 & + & $\begin{array}{l}\text { agreement; areas that burned were more } \\
\text { likely to become shorter }\end{array}$ \\
\hline $\begin{array}{l}\text { Fire vs. no fire in } \\
\text { flatwoods }\end{array}$ & $\psi^{\mathrm{TmSh}}$ & 1.09 & 0.01 & 2.18 & + & $\begin{array}{l}\text { agreement; areas that burned were more } \\
\text { likely to become shorter }\end{array}$ \\
\hline $\begin{array}{l}\text { Cutting vs. no cutting in } \\
\text { scrub }\end{array}$ & $\psi^{\mathrm{TmSh}}$ & 0.66 & 0.07 & 1.25 & + & $\begin{array}{l}\text { agreement; cut areas were more likely } \\
\text { to become shorter }\end{array}$ \\
\hline $\begin{array}{l}\text { Cutting vs. no cutting in } \\
\text { flatwoods }\end{array}$ & $\psi^{\mathrm{TmSh}}$ & 2.39 & 1.80 & 2.97 & + & $\begin{array}{l}\text { agreement; cut areas were more likely } \\
\text { to become shorter }\end{array}$ \\
\hline Edge vs. no edge & $\psi^{\mathrm{TmSh}}$ & -2.07 & -2.56 & -1.58 & - & agreement; edges burned poorly \\
\hline Flatwoods not scrub & $\psi^{\mathrm{TmOp}}$ & 0.86 & -1.30 & 3.03 & + & $\begin{array}{l}\text { agreement; flatwoods burned more } \\
\text { extensively than scrub }\end{array}$ \\
\hline Fire vs. no fire in scrub & $\psi^{\mathrm{TmOp}}$ & 2.16 & 0.15 & 4.17 & + & $\begin{array}{l}\text { agreement; areas that burned were more } \\
\text { likely to become shorter }\end{array}$ \\
\hline $\begin{array}{l}\text { Fire vs. no fire in } \\
\text { flatwoods }\end{array}$ & $\psi^{\mathrm{TmOp}}$ & 0.10 & -0.95 & 1.15 & + & $\begin{array}{l}\text { agreement; areas that burned were more } \\
\text { likely to become shorter }\end{array}$ \\
\hline $\begin{array}{l}\text { Cutting vs. no cutting in } \\
\text { scrub }\end{array}$ & $\psi^{\mathrm{TmOp}}$ & 0.83 & 0.23 & 1.43 & + & $\begin{array}{l}\text { agreement; cut areas were more likely to } \\
\text { become shorter }\end{array}$ \\
\hline $\begin{array}{l}\text { Cutting vs. no cutting in } \\
\text { flatwoods }\end{array}$ & $\psi^{\mathrm{TmOp}}$ & 1.11 & 0.16 & 2.06 & + & $\begin{array}{l}\text { agreement; cut areas were more likely to } \\
\text { become shorter }\end{array}$ \\
\hline Edge vs. no edge & $\psi^{\mathrm{TmOp}}$ & -0.86 & -1.49 & -0.23 & - & agreement; edges burned less extensively \\
\hline Flatwoods not scrub & $\psi^{\mathrm{TmTa}}$ & 1.14 & -0.39 & 2.68 & + & agreement; flatwoods grew faster \\
\hline Flatwoods not scrub & $\psi^{\mathrm{TaSh}}$ & -0.15 & -2.94 & 2.64 & - & $\begin{array}{l}\text { agreement; flatwoods burned more } \\
\text { extensively }\end{array}$ \\
\hline Flatwoods not scrub & $\psi^{\mathrm{TaTm}}$ & 0.84 & 0.08 & 1.60 & + & $\begin{array}{l}\text { agreement; flatwoods burned more } \\
\text { extensively }\end{array}$ \\
\hline
\end{tabular}

Notes: $\hat{\beta}_{j}$ is the estimated slope parameter of the linear-logistic relationship between the specified habitat covariate and transition probability. The superscripts refer to short, optimal, tall mixed, and tall states denoted as, respectively, Sh, Op, Tm, and Ta. Individual $\beta_{j}$ represent covariates (e.g., edge) specific to particular transitions. Fire and cutting $\beta_{j}$ were specific to either scrub or flatwoods where subscripts were identified (i.e., fire $\times$ oak; cutting $\times$ oak). Oak covariate coding: 1 , flatwoods; 0 , scrub. A minus sign indicates a predicted negative $\beta_{j}$, and a plus sign indicates a predicted positive $\beta_{j}$.

For $\psi^{\text {ShOp }}$ and $\psi^{\text {OpSh }}$, we excluded covariates if there were three or fewer cases of a transition for each covariate condition. We also excluded fire for the $\psi^{\mathrm{OpSh}}$ transitions, because there were no occurrences of this transition when Op did not burn.

The Nagelkerke $R^{2}$ provides a close analog to a regression multiple $R^{2}$ for any model for which the maximum likelihood can be calculated (Nagelkerke 1991, Anderson 2008). We calculated Nagelkerke $R^{2}$ to assess the explanatory power for the best-supported model (that with the lowest corrected Akaike information criterion $\left.\left[\mathrm{AIC}_{\mathrm{c}}\right]\right)$ using a time constant model having state-specific transitions with no ecological covariates as the null.

How ecological covariates influence transition probabilities.-Based on previous Florida Scrub-Jay habitat studies, we developed a priori predictions about how each ecological covariate, described in Background and hypotheses above, influenced each transition probability. We stated these a priori predictions by specifying whether coefficients representing each ecological covariate would increase or decrease each transition probability (i.e., we predicted whether the $\beta$ coefficients would be positive or negative; Table 1).

Projecting future habitat dynamics.-We projected habitat dynamics for 35 years to predict the proportion of potential territories (grid cells) in a source (optimal) vs. sink (short, tall mixed, tall) state. We projected these dynamics separately for scrub and flatwoods using three alternative approaches to management: infrequent fire, frequent fire, and frequent fire and cutting. We started 


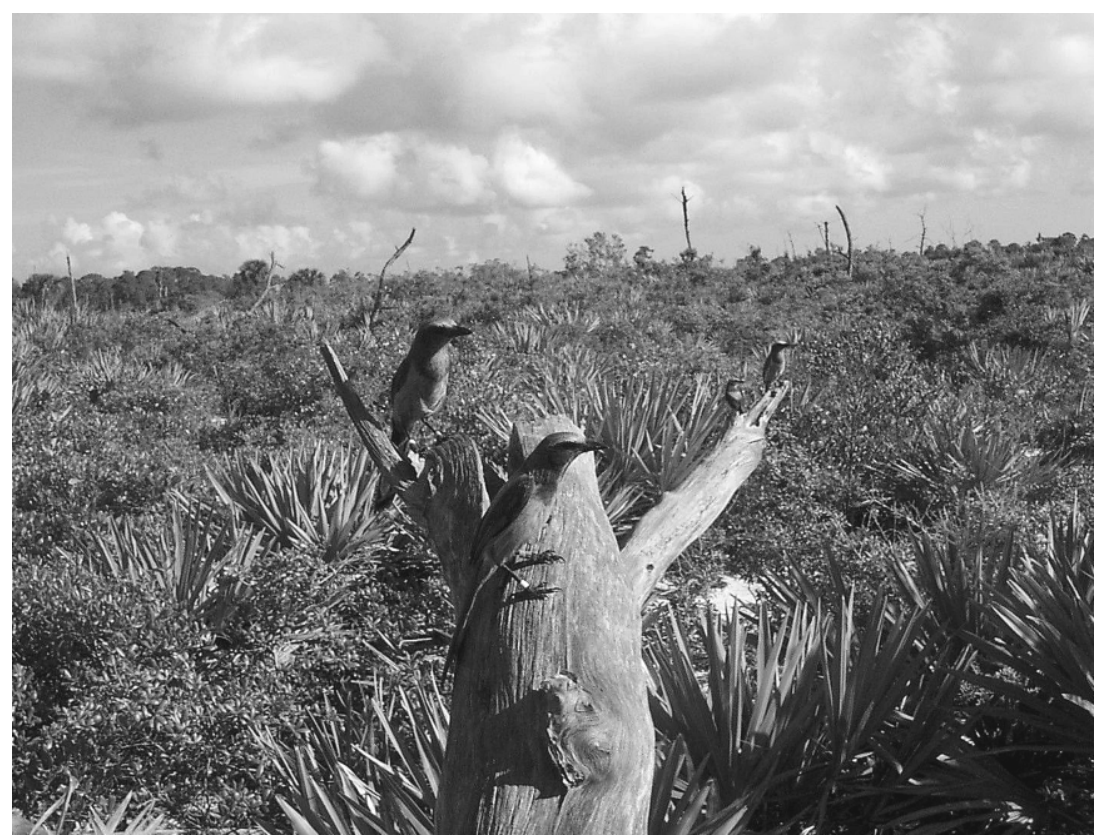

Plate 1. Two pairs of Florida Scrub-Jays aligned along their territory boundary in optimal scrub at Tel-4, Kennedy Space Center/Merritt Island National Wildlife Refuge, Florida, USA. We classified habitat state at the territory scale, which was the geographic unit directly related to recruitment and survival. Using controlled fires and mechanical cutting, management strives to attain most potential territories (grid cells) in source state (recruirment exceeds mortality; optimal) than sink states (mortality exceeds recruitment; short, tall mix, tall). Photo credit: D. R. Breininger.

each projection with a landscape of 1000 grid cells characterized by the same relative abundances of habitat states as found in 2004. We specified the time frame of each projection as the number of five-year intervals (denoted as $m$ ) into the future. Using 2004 as a basis, the expression used to project dynamics is modified to deal with time intervals $>1$ as $n_{04+5 m}=\Psi_{t}^{m} n_{04}$.

We projected dynamics for: (1) infrequently burned scrub, (2) frequently burned scrub, (3) frequently burned and mechanically cut scrub, (4) infrequently burned flatwoods, (5) frequently burned flatwoods, and (6) frequently burned and cut flatwoods. The six matrices for transitions associated with different treatments are provided in Appendix $\mathrm{C}$ and were based on transition probabilities from the best (low$\mathrm{AIC}_{\mathrm{c}}$ ) model for transition probabilities. The frequently burned scenario referred to at least one controlled fire during each five-year interval. The burned and cut scenario referred to mechanical cutting and one fire during each five-year interval. The infrequently burned scenario involved sampling transition probabilities from burned grid cells with a probability of 0.333 and unburned grid cells with a probability of 0.666 . We used random sampling instead of alternating burned and unburned treatments because fire intervals varied greatly among sites in this system (Duncan et al. 2009) and such irregular frequencies are recommended over regular fire intervals (Menges 2007). The infrequently burned scenario simulates a fire regime typically recommended for mixtures of scrub and flatwoods, which has been predicted to be inadequate for restoring degraded habitat (Breininger et al. 2002).

If $m$ becomes sufficiently large in the above projections the landscape expressing the number of sites in each habitat class $\left(\mathbf{n}_{04+5 m}\right)$ stabilizes and becomes a constant, analogous to a stable age distribution in population projection (Caswell 2001). We projected for seven steps because we were interested in projections into the near future (seven steps) and not asymptotic values because habitat management practices do not remain constant for long.

\section{RESUlts}

Comparing models of habitat transition probabilities.Oak, edge, fire, and cutting, but not fire history, were in the model that received virtually all support $\left(\mathrm{AIC}_{\mathrm{c}}\right.$ weight $[w] \sim 1.00$; Appendix A). This "best model" specified the interactions oak $\times$ fire and oak $\times$ cutting, indicating that the effects of fire and cutting differed between scrub and flatwoods vegetative communities. Hereafter, all inferences about transition probability parameters were derived from this model. The Nagelkerke $R^{2}$ value of this model was 0.39 and provides an estimate of variation explained by the best model, relative to that explained by the null model that excluded all ecological covariates (oak, fire, edge, oak $\times$ fire, oak $\times$ cutting).

How ecological covariates influence transition probabilities.-We used Table 1 to compare our a priori 
TABLE 2. Estimated transition probabilities for burned, unburned, and cut scrub and flatwoods at the Kennedy Space Center, Florida, USA, 1994-2004, based on the top model (oak $\times$ fire + oak $\times$ cutting + edge).

\begin{tabular}{|c|c|c|c|c|}
\hline Label & Estimate & Lower CL & Upper CL & Groups \\
\hline$\psi^{\mathrm{ShSh}}$ & 0.45 & 0.29 & 0.61 & burned scrub \\
\hline$\psi^{\text {ShSh }}$ & 0.34 & 0.07 & 0.61 & unburned scrub \\
\hline$\psi^{\text {ShSh }}$ & 0.73 & 0.61 & 0.85 & burned flatwoods \\
\hline$\psi^{\text {ShSh }}$ & 0.28 & 0.12 & 0.44 & unburned flatwoods \\
\hline$\psi^{\text {ShOp }}$ & 0.52 & 0.36 & 0.67 & burned scrub \\
\hline$\psi^{\mathrm{ShOp}}$ & 0.63 & 0.34 & 0.85 & unburned scrub \\
\hline$\psi_{\mathrm{ShOp}}$ & 0.25 & 0.16 & 0.37 & burned flatwoods \\
\hline$\psi^{\text {ShOp }}$ & 0.70 & 0.51 & 0.84 & unburned flatwoods \\
\hline$\psi_{\mathrm{ShTm}}$ & 0.03 & 0.01 & 0.11 & scrub \\
\hline$\psi^{\mathrm{ShTm}}$ & 0.02 & 0.01 & 0.08 & flatwoods \\
\hline$\psi^{\mathrm{OpSh}}$ & 0.11 & 0.07 & 0.18 & scrub \\
\hline$\psi^{\mathrm{OpSh}}$ & 0.20 & 0.13 & 0.30 & flatwoods \\
\hline$\downarrow^{\mathrm{OpOp}}$ & 0.83 & 0.77 & 0.89 & scrub \\
\hline$\psi^{\text {OpOp }}$ & 0.63 & 0.53 & 0.73 & flatwoods \\
\hline$\psi^{\mathrm{OpTm}}$ & 0.06 & 0.03 & 0.11 & scrub \\
\hline$\psi^{\mathrm{OpTm}}$ & 0.17 & 0.11 & 0.25 & flatwoods \\
\hline$\psi^{\mathrm{TmSh}}$ & 0.11 & 0.08 & 0.15 & scrub burned but not cut \\
\hline$\psi^{\text {TmSh }}$ & 0.01 & 0.00 & 0.07 & scrub not burned or cut \\
\hline$\psi^{\mathrm{TmSh}}$ & 0.19 & 0.13 & 0.27 & scrub cut and burned \\
\hline$\psi^{\text {TmSh }}$ & 0.06 & 0.04 & 0.09 & flatwoods burned but not cut \\
\hline$\psi^{\mathrm{TmSh}}$ & 0.02 & 0.01 & 0.06 & flatwoods not burned or cut \\
\hline$\psi^{\mathrm{TmSh}}$ & 0.41 & 0.32 & 0.52 & flatwoods cut and burned \\
\hline$\psi^{\mathrm{TmOp}}$ & 0.09 & 0.07 & 0.13 & scrub burned but not cut \\
\hline$\psi^{\mathrm{TmOp}}$ & 0.01 & 0.00 & 0.08 & scrub not burned or cut \\
\hline$\psi^{\mathrm{TmOp}}$ & 0.19 & 0.13 & 0.27 & scrub cut and burned \\
\hline$\psi^{\text {TmOp }}$ & 0.03 & 0.02 & 0.05 & flatwoods burned but not cut \\
\hline$\psi^{\text {TmOp }}$ & 0.03 & 0.01 & 0.06 & flatwoods not burned or cut \\
\hline$\psi^{\mathrm{TmOp}}$ & 0.09 & 0.04 & 0.17 & flatwoods cut and burned \\
\hline$\psi^{\mathrm{TmTm}}$ & 0.79 & 0.75 & 0.83 & scrub burned but not cut \\
\hline$\psi^{\mathrm{TmTm}}$ & 0.97 & 0.93 & 1.01 & scrub not burned or cut \\
\hline$\psi^{\mathrm{TmTm}}$ & 0.62 & 0.54 & 0.70 & scrub cut and burned \\
\hline$\psi^{\mathrm{TmTm}}$ & 0.90 & 0.88 & 0.92 & flatwoods burned but not cut \\
\hline$\psi^{\mathrm{TmTm}}$ & 0.94 & 0.90 & 0.98 & flatwoods not burned or cut \\
\hline$\psi^{\mathrm{TmTm}}$ & 0.49 & 0.39 & 0.59 & flatwoods cut and burned \\
\hline$\psi^{\mathrm{TmTa}}$ & 0.00 & 0.00 & 0.02 & scrub \\
\hline$\psi^{\mathrm{TmTa}}$ & 0.01 & 0.01 & 0.02 & flatwoods \\
\hline$\psi^{\text {TaSh }}$ & 0.01 & 0.00 & 0.10 & scrub \\
\hline$\psi^{\mathrm{TaSh}}$ & 0.01 & 0.00 & 0.08 & flatwoods \\
\hline$\psi^{\mathrm{TaTm}}$ & 0.19 & 0.11 & 0.30 & scrub \\
\hline$\psi^{\mathrm{TaTm}}$ & 0.35 & 0.25 & 0.46 & flatwoods \\
\hline$\psi^{\mathrm{TaTa}}$ & 0.80 & 0.70 & 0.90 & scrub \\
\hline$\psi^{\mathrm{TaTa}}$ & 0.64 & 0.54 & 0.74 & flatwoods \\
\hline
\end{tabular}

Note: The superscripts refer to short, optimal, tall mixed, and tall states denoted as, respectively, Sh, Op, Tm, and Ta.

predictions of whether ecological covariates would have a positive vs. negative effect on transition probabilities with the signs of the actual coefficients $\left(\hat{\beta}_{j}\right)$ specified in the best model. The signs of all $\hat{\beta}_{j}$ were consistent with a priori predictions for all ecological covariates except ShOp, which had a CI that overlapped zero. Tall and tall mixed grid cells often remained within the same state, in contrast to short and optimal grid cells, which commonly transitioned between one another (i.e., $\psi^{\text {ShOp }}$ and $\psi^{\mathrm{OpSh}}$; Table 2). Fire had a greater influence on $\psi^{\mathrm{ShOp}}$, $\psi^{\mathrm{OpSh}}$, and $\psi^{\mathrm{OpTm}}$ in the more flammable flatwoods than in oak scrub (Table 2). In oak scrub, fire had a much greater influence on $\psi^{\mathrm{TmSh}}$ and $\psi^{\mathrm{TmOp}}$ than in flatwoods. Cutting increased $\psi^{\mathrm{TmSh}}$ and $\psi^{\mathrm{TmOp}}$ for both oak scrub and flatwoods.

Projecting future habitat dynamics.-Projected habitat states changed little in scrub and flatwoods burned infrequently (Fig. 2). The influence of fire without mechanical cutting in scrub produced greater change compared to flatwoods, where mechanical cutting resulted in a much greater increase in the short state (Sh) relative to scrub.

\section{DisCusSION}

Multistate modeling of habitat state transitions provided estimates of transition probabilities, associated measures of precision, and an objective approach for discriminating among alternative hypotheses that specified the influences of ecological covariates. Static site features (i.e., presence of oak and edge) and management activities (i.e., fires and cutting) had important influences on habitat transition probabilities. The influences of static site features and management have also been found to be important in other ecosystems 

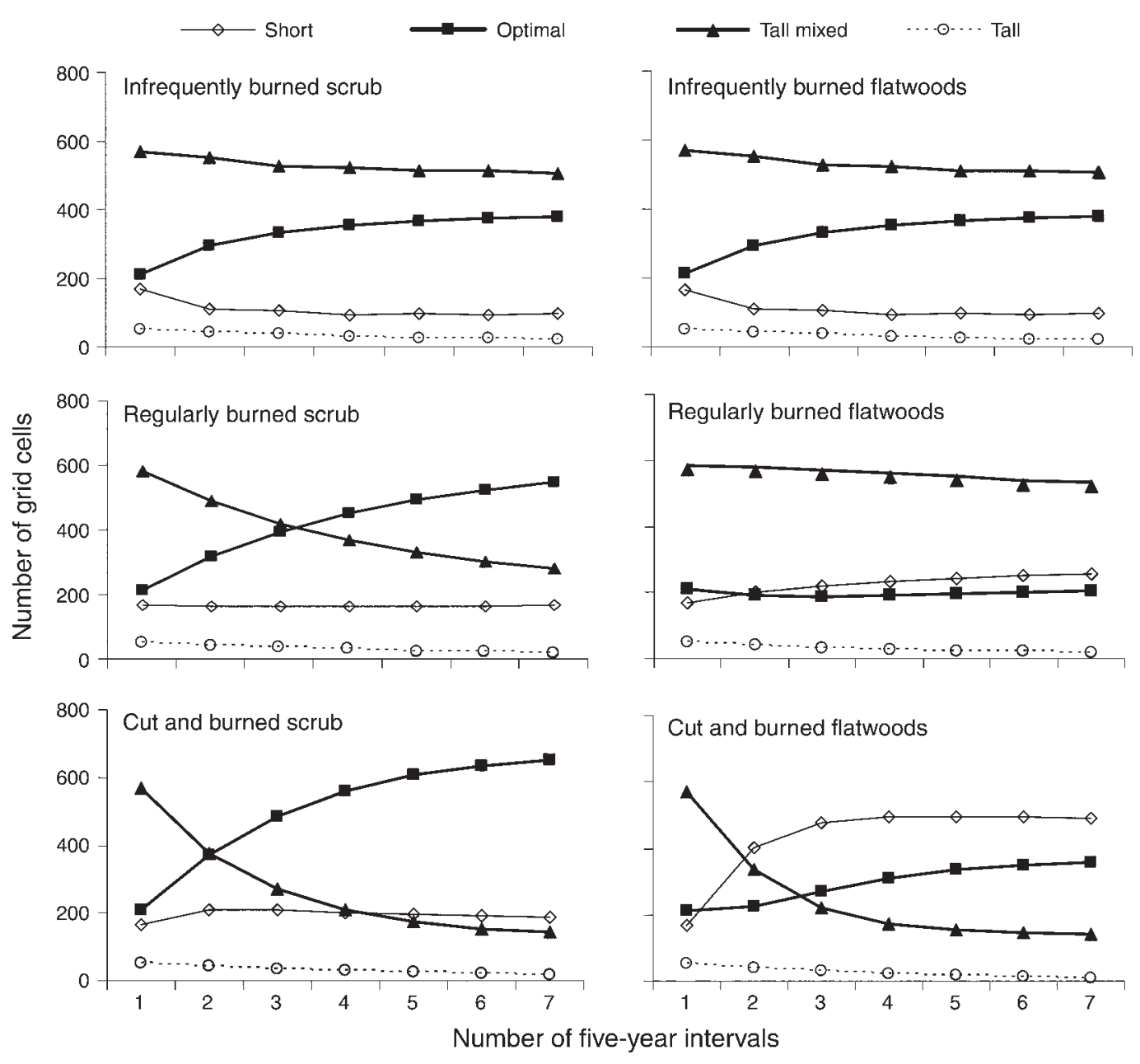

FIG. 2. Projection of management actions across time using transition matrices estimated using multistate models with data from scrub and flatwoods at the Kennedy Space Center, Florida, USA, for 1994, 1999, and 2004. The regularly burned scenario refers to a management regime that includes at least one controlled fire in every five-year interval in contrast to an infrequently burned scenario that includes a controlled fire occurring with a probability of 0.333 for each five-year interval. The cut and burned scenario refers to mechanical cutting of tall scrub and at least one controlled fire during every five-year interval.

(McClanahan et al. 2002, Henkin et al. 2007, Wondzell et al. 2007). Our results were similar to those of Pueyo and Begueria (2007) in Spain, where large differences in transitions occurred across short distances because of site features. In our study, differences were the result of transition probabilities that varied by oak and edge, causing effects of management actions to be influenced by local site features.

The covariate oak was consistently one of the most important ecological factors in predicting transition probabilities. Oak described vegetation differences associated with soils and topography and not human landscape influences. Results supported our a priori predictions that flatwoods would be more dynamic (i.e., have larger transition probabilities from one state to another) than scrub. We predicted this because flatwoods vegetation was more flammable and had shrubs that grew faster after fire, due to the water table being closer to the surface compared to scrub (Schmalzer and Hinkle 1992, Breininger et al. 2002). The covariates fire and cutting were management actions best modeled as interactions with the covariate oak, because the magnitudes of their effects varied depending on whether grid cells were scrub or flatwoods.

Results supported our a priori predictions that edges had a negative effect on transitions to a shorter state $\left(\psi^{\mathrm{OpSh}}, \psi^{\mathrm{TmSh}}\right.$, and $\left.\psi^{\mathrm{TmOp}}\right)$ and a positive effect on transitions to a taller state $\left(\psi^{\text {ShOp }}\right)$, because edges reduced fire spread and frequency. Edge effects in our study system differed from effects in grasslands and tropical forest, where edges increase fire spread due to human-caused fires (Knick and Rotenberry 1997, Laurance 2003). Most edges in our system resulted from direct habitat fragmentation (e.g., roads) or indirect fragmentation effects. Indirect fragmentation effects occurred when scrub, flatwoods, and marshes transi- 
tioned to forests $20-40$ years prior to the study during a management period when all fires were suppressed (Duncan and Schmalzer 2004, Duncan et al. 2004). If our study had included the longer period when scrub or flatwoods transitioned to forests, we could have treated forests as an absorbing state and estimated the transition of scrub and flatwoods to forest (Appendix B).

Resiliency is generally a desirable characteristic for functional natural ecosystems (Pascual and Guichard 2005), but not for degraded aquatic systems resilient to restoration (Carpenter and Lathrop 2008). Tall mixed and tall habitat were resilient to becoming optimal, and there may be many other examples among terrestrial systems subject to anthropogenic fire regime shifts that are difficult to restore (Parisien and Moritz 2009). One possible reason why fire history was not in the best model was that we only modeled its effects for $\psi^{\text {TmSh }}$ and $\psi^{\text {TmOp }}$ due to limited data. As our data increases with time and we have more $\psi^{\text {ShOp }}$ data, we can test whether fire history covariates influence $\psi^{\text {ShOp }}$ because frequent fires should deplete underground biomass slowing oak growth.

Without mechanical cutting, habitat quality projections into the next 15 years predicted that most potential territories were likely to remain in states where Florida Scrub-Jay mortality exceeded recruitment (short, tall mixed, tall; Breininger and Carter 2003, Breininger and Oddy 2004), which is a serious concern for the small, isolated populations that comprise most of the species' range (Stith et al. 1996, Breininger et al. 1999, 2006). Long-term data on Florida Scrub-Jay populations suggest that populations will not persist on lands managed by infrequent fire if the habitat is already in a degraded state (Breininger and Carter 2003). Reports of management progress usually specify acreages burned or cut and provide little to no information on shrub heights at the territory scale or other measures directly related to Florida Scrub-Jay recruitment and mortality. Relevant information on likely management effectiveness was provided by our multistate projections of potential territories (grid cells), which approximated the geographic units at which population recruitment and mortality processes operated.

Burning at least once every five years predicted greater increases in habitat quality in scrub, but not flatwoods, compared to infrequent burning. Long-term data suggest that Florida Scrub-Jay populations persist under frequent fire regimes if the fires are not too extensive and if habitat is not already in a degraded state (Breininger and Oddy 2004). Degraded flatwoods often can only be restored by mechanical cutting once trees become tall enough to be resilient to fire (Duncan et al. 1999). Differences in restoration success using fire alone may have occurred because scrub was dominated by oaks that were usually top-killed by fires, whereas flatwoods were dominated by saw palmetto, whose aboveground rhizomes were not top-killed by fire.
Our transition probability estimates can be used with dynamic optimal control methods to develop optimal management recommendations (Nichols and Williams 2006, McCarthy and Possingham 2007, Martin et al. $2009 b$ ). For example, it is likely that state-specific management, in which decisions about fire and/or cutting are based on Florida Scrub-Jay population and habitat states, will yield outcomes that are superior to those expected based on reliance on regular fire return intervals (F. A. Johnson et al., unpublished manuscript). Management decision making should not only use habitat quality predictions, but should also use Florida Scrub-Jay population abundance and population projections because extensive fires produce many short territories that have especially poor Florida Scrub-Jay survival (Breininger et al. 2009).

There is increased interest in focusing on ecosystem resilience, perturbations, and transient dynamics, but these methods often rely on eigenvalues of the system at equilibrium (Neubert and Caswell 1997, Caswell 2007). Multistate models can not only be used to explicitly test hypotheses about stationarity and stability (e.g., MacKenzie et al. 2003; Appendix B), but they also directly estimate parameters associated with state changes during dynamic periods, such as those that occurred in this study. Multistate models permit direct investigation of underlying processes (Tucker and Anand 2005, Newman et al. 2006, Conn and Cooch 2009) and can accommodate longitudinal data relevant to shifting mosaics, interactions among environmental variables, disturbances, climate oscillations, and climate change (e.g., Callaway and Davis 1993, Scheffer and Carpenter 2003, Van Ness and Scheffer 2005, Whited et al. 2007, Tam and Ang 2008). Multistate modeling of habitat dynamics can also accommodate complications to the observation process such as collection of habitat state data at some periods during an interval of interest but not at others, loss of sample sites (e.g., to an absorbing state), incomplete sampling of sample units, and misclassification(Appendix B).

\section{ACKNOWLEDGMENTS}

This study was funded by NASA. We thank David Anderson, Jim Hines, Mike Legare, Fred Johnson, Reed Noss, Paul Schmalzer, John Weishampel, Pedro Quintana-Ascencio, Carlton Hall, John Shaffer, Steve Brisbin, Denise Thaller, and Burt Summerfield for promoting the study, analyses, and manuscript development.

\section{Literature Cited}

Acevedo, M. F., D. L. Urban, and H. H. Shugart. 1996. Models of forest dynamics based on roles of tree species. Ecological Modelling 87:267-284.

Amarasekare, P., and H. Possingham. 2001. Patch dynamics and metapopulation theory: the case of successional species. Journal of Theoretical Biology 209:333-344.

Anderson, D. R. 2008. Model based inference in the life sciences: a primer on evidence. Springer, New York, New York, USA. 
Augustin, N. H., R. P. Cummins, and D. D. French. 2001. Exploring spatial vegetation dynamics using logistic regression and a multinomial logit model. Journal of Applied Ecology 38:991-1006.

Baker, W. L. 1989. A review of models of landscape change. Landscape Ecology 2:111-133.

Boughton, D., and U. Malvadkar. 2002. Extinction risk in successional landscape subject to catastrophic disturbances. Conservation Ecology 2. 〈http://www.consecol.org/vol6/iss2/ art2〉

Breininger, D. R., M. A. Burgman, and B. M. Stith. 1999. Influence of habitat, catastrophes, and population size on extinction risk on Florida Scrub-Jay populations. Wildlife Society Bulletin 27:810-822.

Breininger, D. R., and G. M. Carter. 2003. Territory quality transitions and source-sink dynamics in a Florida Scrub-Jay population. Ecological Applications 13:516-529.

Breininger, D. R., B. W. Duncan, and N. J. Dominy. 2002. Relationships between fire frequency and vegetation type in pine flatwoods of east-central Florida, USA. Natural Areas Journal 22:186-193.

Breininger, D. R., J. D. Nichols, G. M. Carter, and D. M. Oddy. 2009. Habitat-specific breeder survival of Florida Scrub-Jays: inferences using multistate models. Ecology 90: 3180-3189.

Breininger, D. R., and D. M. Oddy. 2004. Do habitat potential, population density, and fires influence Florida Scrub-Jay source-sink dynamics? Ecological Applications 14:10791089.

Breininger, D. R., M. J. Provancha, and R. B. Smith. 1991. Mapping Florida Scrub-Jay habitat for purposes of land-use management. Photogrammetric Engineering and Remote Sensing 57:1467-1474

Breininger, D. R., B. Toland, D. M. Oddy, and M. L. Legare. 2006. Landcover characterizations and Florida Scrub-Jay (Aphelocoma coerulescens) population dynamics. Biological Conservation 127:169-181.

Buckland, S. T., K. P. Burnham, and N. H. Augustin. 1997. Model selection: an integral part of inference. Biometrics 53: 603-618.

Burnham, K. P., and D. R. Anderson. 2002. Model selection and multimodel inference: a practical information-theoretic approach. Springer-Verlag, New York, New York, USA.

Callaway, R. M., and F. W. Davis. 1993. Vegetation dynamics, fire, and physical environment in coastal central California. Ecology 74:1567-1578.

Carpenter, S. R., and R. C. Lathrop. 2008. Probabilistic estimate of a threshold for eutrophication. Ecosystems 11: 601-613.

Carter, G. M., E. D. Stolen, and D. R. Breininger. 2006. A rapid approach to modeling species-habitat relationships. Biological Conservation 127:237-244.

Caswell, H. 2001. Matrix population models. Second edition. Sinauer, Sunderland, Massachusetts, USA.

Caswell, H. 2007. Sensitivity analysis of transient population dynamics. Ecology Letters 10:1-15.

Conn, P. B., and E. G. Cooch. 2009. Multistate capturerecapture analysis under imperfect state observation: an application to disease models. Journal of Applied Ecology 46:486-492.

Duncan, B. W. 2009. Native fire regime as a reference for establishing management practices. Dissertation. University of Central Florida, Orlando, Florida, USA.

Duncan, B. W., S. Boyle, D. R. Breininger, and P. A. Schmalzer. 1999. Coupling past management practice and historical landscape change on John F. Kennedy Space Center. Landscape Ecology 14:291-309.

Duncan, B. W., V. L. Larson, and P. A. Schmalzer. 2004. Historic and recent landscape change in the North Indian River Lagoon watershed, Florida. Natural Areas Journal 24: $198-215$.
Duncan, B. W., and P. A. Schmalzer. 2004. Anthropogenic influences on potential fire spread in a pyrogenic ecosystem of Florida. Landscape Ecology 19:153-165.

Duncan, B. W., G. Shao, and F. W. Adrian. 2009. Delineating a managed fire regime and exploring its relationship to the natural fire regime in east central Florida, USA: a remote sensing approach. Forest Ecology and Management 258:132-145.

Ellner, S. P., and G. Fussmann. 2003. Effects of successional dynamics on metapopulation persistence. Ecology 84:882889.

Fonnesbeck, C. J. 2006. Spatial modeling of riparian state dynamics in eastern Oregon, USA using discrete event simulation. Landscape and Urban Planning 80:268-277.

Henkin, Z., N. G. Seligman, and I. Noy-Meir. 2007. Successional transitions and management of a phosphorous-limited scrubland ecosystem. Rangeland Ecology and Management 60:453-463.

Hodgson, J. A., A. Moilanen, and C. D. Thomas. 2009. Metapopulation responses to patch connectivity and quality are masked by successional habitat dynamics. Ecology 90: $1608-1619$.

Knick, S. T., and J. T. Rotenberry. 1997. Landscape characteristics of disturbed shrubsteppe habitats in southwestern Idaho (U.S.A.). Landscape Ecology 12:287-297.

Laurance, W. F. 2003. Slow burn: the insidious effects of surface fires on tropical forests. Trends in Ecology and Evolution 18:209-212.

Lebreton, J. D., J. D. Nichols, R. Barker, R. Pradel, and J. Spendelow. 2009. Modeling individual animal histories with multistate capture-recapture models. Advances in Ecological Research 41:87-173.

MacKenzie, D. I., J. D. Nichols, J. E. Hines, M. G. Knutson, and A. B. Franklin. 2003. Estimating site occupancy, colonization, and local extinction when a species is detected imperfectly. Ecology 84:2200-2207.

Martin, J., J. D. Nichols, C. L. McIntyre, G. Ferraz, and J. E. Hines. 2009a. Perturbation analysis for patch occupancy dynamics. Ecology 90:10-16.

Martin, J., M. C. Runge, J. D. Nichols, B. C. Lubow, and W. L. Kendall. 2009b. Structured decision making as a conceptual framework to identify thresholds for conservation management. Ecological Applications 19:1079-1090.

McCarthy, M. A., and H. P. Possingham. 2007. Active adaptive management and conservation. Conservation Biology 21: 956-963.

McClanahan, T., N. Pollunin, and T. Done. 2002. Ecological states and the resilience of coral reefs. Conservation Ecology 6:18. 〈http://www.consecol.org/vol6/iss2/art18/>

Menges, E. S. 2007. Integrating demography and fire management: an example from Florida scrub. Australian Journal of Botany 55:261-272.

Menges, E. S., A. Craddock, J. Salo, R. Conthether, and C. W. Weekley. 2008. Gap ecology in Florida scrub: species occurrence, diversity, and gap properties. Journal of Vegetation Science 19:503-514.

Nagelkerke, N. J. D. 1991. A note on a general definition of the coefficient of determination. Biometrika 78:691-692.

Neubert, M. G., and H. Caswell. 1997. Alternatives to reliance for measuring the responses of ecological systems to perturbations. Ecology 78:653-665.

Newman, K. B., S. T. Buckland, S. T. Lindley, L. Thomas, and C. Fernandez. 2006. Hidden process models for animal population dynamics. Ecological Applications 16:74-86.

Nichols, J. D., J. E. Hines, K. H. Pollock, R. L. Hinz, and W. A. Link. 1994. Estimating breeding proportions and testing hypotheses about costs of reproduction with capturerecapture data. Ecology 75:2052-2065.

Nichols, J. D., and W. L. Kendall. 1995. The use of multi-state capture-recapture models to address questions in evolutionary ecology. Journal of Applied Statistics 22:835-846. 
Nichols, J. D., and B. K. Williams. 2006. Monitoring for conservation. Trends in Ecology and Evolution 21:669-673.

Noss, R. F., M. A. O'Connell, and D. D. Murphy. 1997. The science of conservation planning: habitat conservation under the Endangered Species Act. Island Press, Washington, D.C., USA.

Paine, D. P. 1981. Aerial photography and image interpretation for resource management. John Wiley and Sons, New York, New York, USA.

Parisien, M. A., and M. A. Moritz. 2009. Environmental controls on the distribution of wildfire at multiple spatial scales. Ecological Monographs 79:127-154.

Pascual, M., and F. Guichard. 2005. Criticality and disturbance in spatial ecosystems. Trends in Ecology and Evolution 20: 88-95.

Pueyo, Y., and S. Begueria. 2007. Modeling the rate of secondary succession after farmland abandonment in a Mediterranean mountain area. Landscape and Urban Planning 83:245-254.

Quintana-Ascencio, P. F., and E. S. Menges. 1996. Inferring metapopulation dynamics from patch-level incidence of Florida scrub plants. Conservation Biology 10:1210-1219.

Rutherford, G. N., A. Guisan, and N. E. Zimmermann. 2007. Evaluating sampling strategies and logistic regression methods for modeling complex land cover changes. Journal of Applied Ecology 44:414-424.

Scheffer, M., and S. R. Carpenter. 2003. Catastrophic regime shifts in ecosystems: linking theory to observation. Trend in Ecology and Evolution 18:648-656.

Schmalzer, P. A., and S. R. Boyle. 1998. Restoring longunburned oak-mesic flatwoods requires mechanical cutting and prescribed burning. Restoration and Management Notes 16:96-97.

Schmalzer, P. A., and C. R. Hinkle. 1992. Recovery of oak-saw palmetto after fire. Castanea 57:158-173.

Scott, J. M., et al. 1993. Gap analysis: a geographic approach to protection of biological diversity. Wildlife Monographs 123: $1-41$.

Scott, J. M., P. L. Hedland, M. L. Morrison, J. B. Hauler, M. G. Raphael, W. A. Wall, and F. B. Samson. 2002. Predicting species occurrences issues of scale and accuracy. Island Press, Washington, D.C., USA.

Shao, G., and B. W. Duncan. 2007. Effects of band combinations and GIS masking on fire-scar mapping at local scales in east-central Florida, USA. Canadian Journal of Remote Sensing 33:250-259.

Stith, B. M., J. W. Fitzpatrick, G. E. Woolfenden, and B. Pranty. 1996. Classification and conservation of metapopulations: a case study of the Florida Scrub-Jay. Pages 187-216 in D. R. McCullough, editor. Metapopulations and wildlife conservation. Island Press, Covelo, California, USA.

Tam, T., and P. O. Ang, Jr. 2008. Catastrophic regime shifts in coral communities exposed to physical disturbances: simulation results from object-oriented 3-dimensional coral reef model. Journal of Theoretical Biology 259:193-208.

Thomas, C. D. 1994. Extinction, colonization, and metapopulations: environmental tracking by rare species. Conservation Biology 8:373-378.

Tucker, B. C., and M. Anand. 2005. On the use of stationary versus hidden Markov models to detect simple versus complex ecological dynamics. Ecological Modelling 185:177-193.

Usher, M. B. 1979. Markovian approaches to ecological succession. Journal of Animal Ecology 48:413-426.

Van Horne, B. 1983. Density as a misleading indicator of habitat quality. Journal of Wildlife Management 47:813-901.

Van Ness, E. H., and M. Scheffer. 2005. Implications for spatial heterogeneity for catastrophic regime shifts in ecosystems. Ecology 86:1797-1807.

Waggoner, P. E., and G. R. Stephens. 1970. Transition probabilities for a forest. Nature 255:1160-1161.

White, G. C., and K. P. Burnham. 1999. Program MARK for survival estimation. Bird Study 46:S120-S139.

White, G. C., W. L. Kendall, and R. J. Baker. 2006. Multistate survival models and their extensions in Program MARK. Journal of Wildlife Management 70:1521-1529.

Whited, D. C., M. S. Lorang, M. J. Harner, F. R. Hauer, J. S. Kimball, and J. A. Stanford. 2007. Climate, hydrologic disturbance, and succession: drivers of floodplain pattern. Ecology 88:940-953.

Wondzell, S. M., M. A. Hemstrom, and P. A. Bisson. 2007. Simulating riparian and aquatic habitat dynamics in response to natural and anthropogenic disturbance regimes in the Upper Grande Ronde River, Oregon, USA. Landscape and Urban Planning 80:249-267.

Yemshanov, D., and A. H. Perera. 2003. A spatially explicit stochastic model to simulate boreal forest cover transitions: general structure and properties. Ecological Modelling 150: 189-209.

\section{APPENDIX A}

The competing models and model selection results (Ecological Archives E091-237-A1).

\section{APPENDIX B}

Approaches for constraining multistate capture-recapture models to estimate habitat and landscape transition probabilities (Ecological Archives E091-237-A2).

\section{APPENDIX C}

Transition matrices used to project effects of alternative management scenarios for four habitat states: short, optimal, tall mixed, and tall in two scrub ecosystem habitat types (Ecological Archives E091-237-A3). 